\title{
Dysregulated IGFBP5 expression causes axon degeneration and motoneuron loss in diabetic neuropathy
}

\author{
Christian M. Simon ${ }^{1,7} \cdot$ Stefanie Rauskolb ${ }^{1}$ Jennifer M. Gunnersen ${ }^{1,8}$. \\ Bettina Holtmann ${ }^{1,9} \cdot$ Carsten Drepper $^{1,10} \cdot$ Benjamin Dombert $^{1}$ • \\ Massimiliano Braga $^{1,3,4} \cdot$ Stefan Wiese $^{1,11} \cdot$ Sibylle Jablonka $^{1} \cdot$ Dirk Pühringer $^{1,12}$. \\ Jürgen Zielasek ${ }^{2,13}$ - Andreas Hoeflich ${ }^{5,14} \cdot$ Vincenzo Silani $^{4,15} \cdot$ Eckhard Wolf $^{5}$. \\ Susanne Kneitz ${ }^{6}$ - Claudia Sommer ${ }^{2} \cdot$ Klaus V. Toyka $^{2} \cdot$ Michael Sendtner $^{1}$
}

Received: 30 January 2015 / Revised: 8 May 2015 / Accepted: 14 May 2015 / Published online: 30 May 2015

(C) The Author(s) 2015. This article is published with open access at Springerlink.com

\begin{abstract}
Diabetic neuropathy (DNP), afflicting sensory and motor nerve fibers, is a major complication in diabetes. The underlying cellular mechanisms of axon degeneration are poorly understood. IGFBP5, an inhibitory binding protein for insulin-like growth factor 1 (IGF1) is highly up-regulated in nerve biopsies of patients with DNP. We investigated the pathogenic relevance of this finding in transgenic mice overexpressing IGFBP5 in motor axons and sensory nerve
\end{abstract}

C. M. Simon, S. Rauskolb, and J. M. Gunnersen contributed equally to this manuscript.

Electronic supplementary material The online version of this article (doi:10.1007/s00401-015-1446-8) contains supplementary material, which is available to authorized users.

Michael Sendtner

Sendtner_M@ukw.de

1 Institute for Clinical Neurobiology, University of Würzburg, Versbacher-Str. 5, 97078 Würzburg, Germany

2 Department of Neurology, University of Würzburg, Josef-Schneider-Str. 11, 97080 Würzburg, Germany

3 A.O. Desio e Vimercate, Via Santi Cosma e Damiano 10, 20871 Vimercate, Italy

4 Department of Pathophysiology and Transplantation, "Dino Ferrari" Center, Università degli Studi di Milano, Via Francesco Sforza 35, 20122 Milan, Italy

5 Institute of Molecular Animal Breeding and Biotechnology, Gene Center, LMU Munich, Feodor-Lynen Str. 25, 81377 Munich, Germany

6 Department of Physiological Chemistry I, Biocenter, University of Würzburg, Am Hubland, 97074 Würzburg, Germany

7 Present Address: Motor Neuron Center, Columbia University, 630 West 168th Street, Room 4-401, New York, NY 10032, USA fibers. These mice develop motor axonopathy and sensory deficits similar to those seen in DNP. Motor axon degeneration was also observed in mice in which the IGF1 receptor (IGF1R) was conditionally depleted in motoneurons, indicating that reduced activity of IGF1 on IGF1R in motoneurons is responsible for the observed effect. These data provide evidence that elevated expression of IGFBP5 in diabetic nerves reduces the availability of IGF1 for IGF1R on motor axons, thus leading to progressive neurodegeneration. Inhibition of IGFBP5 could thus offer novel treatment strategies for DNP.

Keywords Motor nerve biopsy $\cdot$ Diabetic polyneuropathy $\cdot$ Neuropathy $\cdot$ Neurotrophic factors $\cdot$ Axonal degeneration

8 Present Address: Department of Anatomy and Neuroscience, The University of Melbourne, Parkville, VIC 3010, Australia

9 Present Address: Central Facility for Biological and Biomedical Research, University of Hohenheim, Schwerzstrasse 15/1, 70593 Stuttgart, Germany

10 Present Address: Department of Child and Adolescent Psychiatry, Psychosomatics, and Psychotherapy, University Hospital of Würzburg, Füchsleinstr.15, 97080 Würzburg, Germany

11 Present Address: Group of Cell Morphology and Molecular Neurobiology, Building NDEF 05/598, Universitätsstr. 150, Ruhr-University Bochum, 44801 Bochum, Germany

12 Present Address: Department for Obstetrics and Gynecology, University of Würzburg, Josef-Schneider-Str. 4, 97080 Würzburg, Germany 


\section{Introduction}

Diabetic neuropathy (DNP) is a heterogeneous disorder, with sensory, motor, and autonomic system involvement [5], including small fiber disease, all leading to progressive disability $[37,40]$. The etiopathogenesis of DNP is complex and involves metabolic, vascular, and immune-mediated components [50], but whether trophic factor dysregulation plays a role is still unclear. In a large study comparing disability in the elderly, motor performance was more reduced in diabetic than non-diabetic individuals and found to make a major contribution to overall disability [45]. In streptozotocin-treated mice, a widely used rodent model of some aspects of DNP, progressive loss of motor fibers becomes apparent with age, with loss of distal axons occurring prior to proximal axons and motoneuron cell bodies [39]. In the same model, reduced insulin-like growth factor 1 (IGF1) expression [53] and elevated renal insulin-like growth factor-binding protein 5 (IGFBP5) levels were found [35], but the relevance of these findings for DNP remained unclear. IGF1 and IGF2 are pluripotent growth and survival factors for a variety of cell types [42]. They support the survival of motoneurons in vitro and in vivo [20, 33]. Igfl knockout mice show multiple defects including reduced myelination and loss of striatal neurons [3]. IGF1 is expressed in Schwann cells of peripheral nerves in developing and postnatal rodents [10]. It acts on Schwann cells, in particular by stimulating myelination $[11,46]$, and possibly also on myelinated axons [31]. In transgenic mice overexpressing IGF1, enhanced myelin production was among the most prominent effects $[9,55]$.

The biological functions of IGF1 and IGF2 are modulated by at least 6 binding proteins (IGFBPs) [14, 27, 54]. Some of these binding proteins are produced in the liver and function as carriers for IGFs in the circulation [13]. Other IGFBPs are expressed in specific tissues and are thought to increase local concentrations of IGFs by trapping circulating IGF1 and/or IGF2, as well as to compete with cellular receptors for IGF binding [1, 24]. Thus, they are potential regulators of the local availability and biological functions of IGFs. IGFBP5, a 29-kDa glycosylated protein [15], is a high affinity binding protein for IGF1, which, at least in vitro, inhibits receptor binding of IGFs resulting in reduced receptor

13 Present Address: Medical Faculties of the Heinrich-Heine University, Bergische Landstraße 2, 40629 Düsseldorf, Germany

14 Present Address: Institute of Genome Biology, Leibniz Institute for Farm Animal Biology (FBN), Wilhelm-Stahl-Allee 2, 18196 Dummerstorf, Germany

15 Present Address: Department of Neurology and Laboratory of Neuroscience, IRCCS Instituto Auxologico Italiano, Piazzale Brescia 20, 20149 Milan, Italy autophosphorylation [26]. IGFBP5 is widely expressed in the body including in the kidney $[35,38]$ and the nervous system $[4,44]$. In postnatal peripheral nerves, IGFBP5 immunoreactivity is detectable in close association with or within myelinated axons, suggesting that it is anterogradely transported and released from axons [12, 46]. IGFBP5 binds with high affinity to extracellular matrix (ECM) [14, 25]. Thus, IGFBP5 may be involved in regulating local functions of IGF1 and IGF2 at the interface between motoneurons and Schwann cells. To study the role of the IGF1/IGFBP5/ IGF1R system for axon maintenance, we investigated alterations of expression of IGFs and IGFBPs in peripheral nerves of patients with DNP and compared them with other neuropathies and healthy controls. We found that IGFBP5 levels are increased in sural nerve biopsies of patients with sensorimotor DNP. To determine the pathogenic role of elevated IGFBP5, we established transgenic mouse lines in which IGFBP5 is overexpressed specifically in neurons under the control of the neurofilament-light chain (NF-L) promoter and found a progressive neuropathy in these mutants that affected both sensory and motor nerve fibers. We also tested whether reduced availability of IGF1 may be responsible for the degeneration of motoneurons by establishing mice in which the IGF1R is inactivated in motoneurons. In these mice, we observed a progressive degeneration of motor axons and cell bodies. These results indicate that elevated expression of IGFBP5 along with inhibition of IGF1 signaling in motoneurons leads to degeneration of their axons and cell bodies and suggest a causative link. Thus, increased expression of IGFBP5 may play a role in the pathogenesis of sensory defects and motor axonopathy associated with DNP.

\section{Materials and methods}

\section{Animals}

The generation of the Igfbp5 tg+ (Bp5 tg+) and cIgflr ko mice is described in the supplementary methods section. Analyses with these mouse lines were performed between the 4th and the 12th generation of backcrossing of these mice onto a $\mathrm{C} 57 \mathrm{Bl} / 6 \mathrm{~J}$ background. Animals were kept in a temperature-controlled environment with a 12-h-light/12h-dark cycle. For details of behavioral analyses see supplementary methods section.

\section{Sural nerve biopsies}

Diagnostic nerve biopsies were obtained from the Department of Neurology, Würzburg. Diabetic neuropathy (DNP, $n=6$, one type I, five type II) was diagnosed according to established criteria [34] after excluding other causes of polyneuropathy [49]. Chronic inflammatory demyelinating 
polyradiculoneuropathy (CIDP, $n=9$ ) was diagnosed according to INCAT criteria [19]. DNP in combination with CIDP [23] was diagnosed in four patients with type II diabetes showing marked motor impairment and prominent demyelination in the sural nerve with reduced nerve conduction velocities thus fulfilling the INCAT criteria [19] for CIDP. All 19 patients had motor nerve abnormalities when tested by standard nerve conduction testing and electromyography [21, 28]. Samples from three patients with non-diabetic neuropathy were included as disease controls: mild axonal neuropathy with motor neuron disease $(n=2)$ and vitamin B12 deficiency $(n=1)$. Non-diseased control tissues $(n=5)$ were taken from biopsy and autopsy material that was checked for absence of pathology. For details see electronic supplementary Table A2.

\section{Immunohistochemistry}

Human nerves were fixed for $24 \mathrm{~h}$ in $4 \%$ PFA at $4{ }^{\circ} \mathrm{C}$. $10 \mu \mathrm{m}$ frozen transverse nerve sections were prepared. Mice were perfused with $4 \%$ PFA and sciatic nerves were dissected. Sections were incubated overnight with primary antibodies: neurofilament (1:500, Covance), IGFBP5 (1:200, Abcam), laminin B1 (1:500; Millipore). Sections were then washed and incubated with secondary antibodies conjugated to FITC (1:40, Dako), Alexa Fluor 633 (1:500, Invitrogen) or Cy3 (1:600, Jackson ImmunoResearch Laboratories, Inc) for $1 \mathrm{~h}$, mounted and investigated with the Olympus FluoView ${ }^{\mathrm{TM}}$ FV1000 microscope.

\section{Motoneuron culture}

Murine embryonic spinal motoneurons were cultured as described [52]. BDNF, human IGF1 (PeProTech) and mouse IGFBP5 (BP5DU020, GroPep) were used at the concentrations indicated. Cells were initially counted $4 \mathrm{~h}$ after plating to obtain the reference value for $100 \%$ survival. After 7 DIV, surviving motoneuron cells were counted again. For IGF1 stimulation experiments, motoneurons were cultured for 5 days with $5 \mathrm{ng} / \mathrm{ml} \mathrm{BDNF}$ in full medium, and then starved in the same medium without horse serum and BDNF for $12 \mathrm{~h}$. Cells were then stimulated with IGF1. Neurons were fixed with $4 \%$ PFA and stained with anti-Tau (1:1000, Sigma) and anti-IGFBP5 (1:500, Neuromics) antibodies. Cellular morphology was visualized with fluorescencecoupled secondary antibodies (Jackson ImmunoResearch) using a Leica SP2 confocal microscope. Measurements were done with the Leica AS Lite software (Leica).

\section{Dorsal root ganglionic (DRG) sensory neuronal culture}

Murine embryonic DRGs were isolated and cultured as described previously [22]. For IGF1 stimulation experiments, DRG neurons were cultured with neurobasal medium (NB) in the presence of $2 \%$ horse serum, $2 \%$ B27 and $10 \mathrm{ng} / \mathrm{ml} \mathrm{NGF} \mathrm{(PeProTech)} \mathrm{for} 20 \mathrm{~h}$. Cells were starved for $4 \mathrm{~h}$ in NB after three washing steps with NB to minimize NGF levels. DRGs were then stimulated with either $10 \mathrm{ng} / \mathrm{ml}$ NGF, $20 \mathrm{ng} / \mathrm{ml}$ human IGF1 (PeProTech) or $20 \mathrm{ng} / \mathrm{ml}$ human IGF1 and $200 \mathrm{ng} / \mathrm{ml}$ mouse IGFBP5 (BP5DU020, GroPep), respectively. Subsequently, cells were washed with phosphate buffer saline and lysed for $10 \mathrm{~min}$ at $4{ }^{\circ} \mathrm{C}$ with lysis buffer comprising $50 \mathrm{mM}$ Tris$\mathrm{HCl}(\mathrm{pH}$ 7.4), $150 \mathrm{mM} \mathrm{NaCl}, 1 \%$ Triton-X-100, Proteaseand Phosphatase inhibitors (Thermo Scientific). Equal volumes of DRG cell lysates were loaded onto $12 \%$ SDS gels and immunoblotted for IGF1R, pIGF1R, AKT, pAKT and calnexin.

\section{Western blot analysis}

Protein was isolated from nerve biopsies homogenized in lysis buffer $(150 \mathrm{mM} \mathrm{NaCl}, 1 \%$ Triton, $2 \mathrm{mM}$ EDTA, $50 \mathrm{mM}$ Tris, $\mathrm{pH}$ 7.4). $30 \mu \mathrm{g}$ protein extract was electrophoresed on a $12 \%$ SDS-PAGE gel and blotted for $40 \mathrm{~min}$ to PVDF membrane. The membranes were probed with rabbit anti-IGFBP5 (H-100, 1:5000, Santa Cruz Biotechnology) for human samples and goat anti-IGFBP5 antibody (GT15183, 1:5000, Neuromics) for murine samples in $5 \%$ skim milk, and rabbit anti-phosho-IGF1 receptor beta (3918, 1:2000) in $5 \%$ BSA, anti-IGF1 receptor beta (3027, 1:2000) in $5 \%$ milk, for immunoprecipitation 1:1000 in combination with protein A agarose beads (11719386001, Roche), anti-phospho-Akt (9271, 1:2000 in 5\% BSA) and anti-Akt (9272, 1:2000 in $5 \%$ milk, all from Cell Signaling Technology) for mouse extracts, in blocking buffer for $1 \mathrm{~h}$. The appropriate HRP-conjugated secondary antibody (Jackson ImmunoResearch Laboratories, Inc) was used and visualized using enhanced chemiluminescence (GE Healthcare, Lifesciences). The blots were reprobed with mouse anti-actin antibody (Clone C4, 1:7000, Millipore). Film images were scanned and the intensity of IGFBP5 was standardized to mouse anti-actin. A minimum of $n=3$ per group were tested in 3 independent experiments.

\section{Quantitative morphometry on cross sections of the phrenic and sciatic nerve}

The morphological analysis of phrenic and sciatic nerve axons was carried out in Igfbp 5 transgenic mice derived from mouse line 8 at 3 weeks (wt: $n=4 ; B p 5 t g+: n=6$ ) and 5 to 6 months (wt: $n=5 ; B p 5 t g+: n=3$ ) of age and in 5- to 6-month-old transgenic mice derived from mouse line $9(n=3)$. In addition, the phrenic and sciatic nerve axons were analyzed in 4 cIgflr ko and 4 wild-type mice at 6 months of age. Mice were transcardially perfused with 
$0.1 \mathrm{M}$ phosphate buffer followed by a mixture of $4 \%$ paraformaldehyde and $2 \%$ glutaraldehyde in $0.1 \mathrm{M}$ cacodylate buffer. The proximal part of the phrenic nerves was then dissected and postfixed in the same fixative overnight. After osmification and dehydration, all samples were embedded in Spurr`s medium. Semithin $(1 \mu \mathrm{m})$ cross sections for light microscopic examination were cut with a diamond knife on an ultramicrotome. Sections were stained with azur-methylene blue for histomorphological analysis and subsequent morphometric evaluation. The nerve sections of Igfbp5 $t g+$ mice were analyzed under a light microscope (Leica $\mathrm{GmbH}$, Bensheim, Germany) and morphometric evaluation of phrenic and sciatic nerves was performed using the Quantimed 500 morphometric system (Leica GmbH, Bensheim, Germany). The number of intact myelinated fibers in motoneuron-specific Igflr mutant mice was determined from photographs taken from nerve cross sections under an Leica (Nussloch, Germany) light microscope equipped with a digital camera (ActionCam; Agfa, Mortsel, Belgium). To estimate the total number and relative axon size distributions in sciatic nerves, 4 cIgflr $k o$ and 4 wild-type mice were prepared as described above. A segment of the main sciatic nerve trunk was taken from a standard site. Cross sections were photographed using a Zeiss Axiophot microscope in conjugation with a digital Spot Insight Camera with corresponding Spot Software (Visitron Systems $\mathrm{GmbH}$, Puchheim, Germany). The stereological analysis of myelinated axons was carried out on a Vario Vision Docu software analysis system (Vario Vision Docu; Soft Imaging System, Münster, Germany). To obtain unbiased number and size estimates from a sample of axons in a nerve cross section, we followed the concept of systematic random sampling using a systematically positioned unbiased counting frame [18]. The entire nerve cross sections were photographed at low magnification $(200 \times)$ and the entire nerve cross section areas were determined. Approximately 10 high magnification photomicrographs $(1000 \times)$ were taken from each nerve cross section. The counting frame $\left(2500 \mu \mathrm{m}^{2}\right)$ was systematically placed into the lower right corner of each photomicrograph covering at least one-half of the nerve cross section. Axons in the frame or at the (dashed) inclusion lines were counted provided that they do not in any way touch the (solid) exclusion lines or their infinite extensions. Approximately 300-600 axons were counted in 6-8 micrographs per nerve cross section. Estimates of the total number of axons were calculated as: total number of axons counted divided by the product of number and area of the counting frames multiplied by the area of the nerve cross section. Absolute and relative size distributions of myelinated axons were measured on the same photomicrograph so that number and size estimations were combined into one complete procedure. The cross-sectional area of the axons was determined by tracing them with a cursor on a digitizing tablet of the Vario Vision Docu analysis system. The M-ratio was calculated by the division of myelin thickness by axon diameter. At least 150 M-ratios and circumferences per nerve were measured in at least 3 individuals per group.

\section{Intraepidermal nerve fiber density (IENFD)}

Foot pads were collected from the plantar surface of the hind paw, immersion fixed with $4 \%$ paraformaldehyde for $2 \mathrm{~h}$, cryoprotected overnight in $30 \%$ sucrose, cryoembedded in mounting media (OCT), and $12 \mu \mathrm{m}$ cryostat sections were prepared. Sections were labeled using rabbit polyclonal antibodies against PGP9.5 (1:800, Ultra clone limited, RA95101) and donkey anti-rabbit $(\mathrm{H}+\mathrm{L})$ IgG Cy3-conjugated secondary antibodies (1:700, Jackson Immunoresearch). Images were acquired using a Leica SP2 confocal microscope system (Leica Microsystems) and a $40 \times$ oil immersion objective. Eight confocal images were captured at $1 \mu \mathrm{m}$ intervals and an average projection image was produced by ImageJ (MacBiophotonics). Images were analyzed using the Leica LAS AF Lite software. Individual intraepidermal nerve fibers which passed through the basement membrane were scored from individual sections of independent animals. In total, 16 sections from footpads from 4 wild-type and 21 sections from footpads from 4 Igfbp 5 transgenic mice were scored. IENFD data are presented and statistically analyzed as the mean number of nerve fibers per $\mathrm{mm}^{2}$ of epidermis. For visual presentation, linear brightness and contrast correction was performed consistently in the corresponding images without changing image information.

\section{Electrophysiology}

Analyses of nerve conduction studies were initially performed with a Toennies electromyograph (Toennies, Würzburg) and later with a digital Neurosoft-Evidence 3102 electromyograph (Schreiber \& Tholen Medizintechnik). Motor and compound sensory-motor nerve conduction was investigated in the sciatic nerve in mutant and control mice using techniques described previously for numerous mutant mouse lines [6, 29, 57]. For details see supplementary methods section.

\section{Statistical analysis}

All data are expressed as mean $\pm \mathrm{SD}\left({ }^{*} P<0.05\right.$, $* * P<0.01, * * * P<0.001)$. For statistical analysis, 3 independent experiments were conducted. After testing for normal distribution, the data were subjected to a statistical analysis with two-tailed Student's $t$ test when comparing two groups and one-way ANOVA with the Tukey post hoc 
Fig. 1 IGFBP5 protein levels are significantly up-regulated in biopsies of DNP patients. a Western blots of IGFBP5 protein levels in human sural nerve from control $(C)$ individuals (3 samples shown from a total of 5 analyzed), patients (P) with DNP, CIDP, DNP+CIDP (3 samples shown from 4 in total) and other neuropathies (ONP; axonal neuropathy in motor neuron disease $(\mathrm{O} 1, \mathrm{O} 3)$, vitamin $\mathrm{B} 12$ deficiency $(\mathrm{O} 2)$. b IGFBP5 protein levels were specifically up-regulated in patients with DNP. Biopsies of patients with DNP showed on average a 5-fold up-regulation compared to CIDP individuals and 50-fold in comparison to healthy controls. Up-regulation in DNP patients with additional CIDP was not significantly higher than in patients with DNP alone. Other neuropathies (ONP) and patients with CIDP showed no significant change in comparison to controls. All values were normalized to CIDP biopsies. QL: quantitative labeling. c IGFBP5 (green) and neurofilament (red) distribution in human sural nerves from a control individual and a patient with DNP. Note that IGFBP5 levels were increased in axons and in the extracellular matrix (ECM) (arrows) in DNP. Scale bar $5 \mu \mathrm{m}$
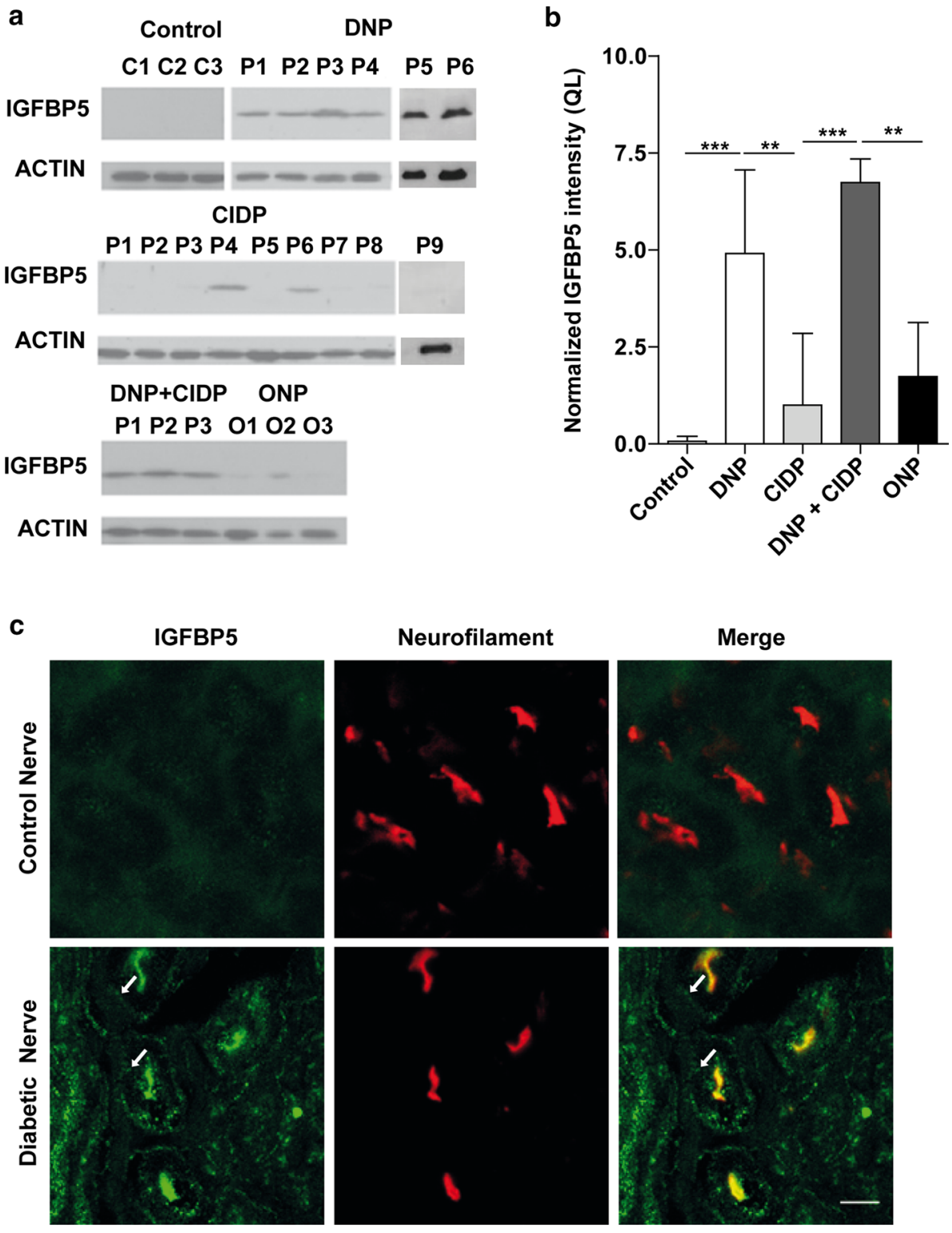

test for comparison of more than 2 groups. The frequency distribution of axon circumferences was analyzed by twoway ANOVA with the Bonferroni post hoc test. Statistical analysis was performed with Graph Pad Prism4 Software (San Diego, USA). Final figures were arranged using ImageJ, Adobe Photoshop and Adobe Illustrator CS6.

\section{Results}

\section{IGFBP5 protein levels are elevated in nerve biopsies in DNP}

Previous studies have shown that IGF1 levels are downregulated in peripheral nerves in diabetic [53] and nondiabetic [16] types of neuropathy. We therefore investigated the expression of IGF family members, their receptors and IGFBPs by microarray expression analysis of sural nerve biopsies from patients with DNP and age-matched control individuals (electronic supplementary Table A1). Microarray expression analysis revealed a decrease of $I G F 1$ mRNA levels and more than sevenfold up-regulation of IGFBP5 expression in DNP. These findings were corroborated by Western blotting using protein extracts from sural nerve biopsies (Fig. 1a). IGFBP5 protein levels were more than 5 -fold up-regulated in 6 patients with DNP $(P<0.01$, oneway ANOVA) (see electronic supplementary Table 2 for clinical characteristics of these patients) and in 3 patients with combined diabetic neuropathy and chronic inflammatory demyelinating polyradiculoneuropathy (DNP+CIDP; $P<0.001$, one-way ANOVA) as compared to CIDP individuals (Fig. 1b, c) and 50-fold in comparison to healthy 
controls $(P<0.001$, one-way ANOVA). Increased IGFBP5 protein levels were only observed in 2 out of 9 CIDP patients, and did not reach statistical significance when compared with controls ( $P>0.05$, one-way ANOVA). This suggests an association of IGFBP5 overexpression with DNP rather than with the superimposed CIDP in this mixed group. IGFBP5 expression was also low in the 3 patients with non-diabetic neuropathy ( $P>0.05$, one-way ANOVA) (Fig. 1a, b). This indicates that levels of IGFBP5 are specifically up-regulated in patients with DNP. Enhanced levels of IGFBP5 could also be detected by immunohistochemistry in peripheral nerve sections (Fig. 1c), particularly in axons, as revealed by co-localization with neurofilament $\mathrm{H}$ immunoreactivity. IGFBP5 immunoreactivity was also observed in the extracellular matrix surrounding the axons (arrows in Fig. 1c).

\section{IGFBP5 inhibits motoneuron survival and axon growth}

Based on the significant up-regulation of IGFBP5 expression in nerves of diabetic patients, we investigated whether IGFBP5 interferes with the effects of IGF1 on cultured spinal motoneurons, grown for 7 days with IGF1 or BDNF $(5 \mathrm{ng} / \mathrm{ml})$ alone, or in combination with IGFBP5 (80 ng/ $\mathrm{ml})$. IGF1 and BDNF had potent effects on motoneuron survival ( $P<0.001$, one-way ANOVA). IGF1 maintained $43 \%$ of initially plated motoneurons; BDNF maintained $50 \%$ (Fig. 2a). Addition of IGFBP5 $(80 \mathrm{ng} / \mathrm{ml})$ reduced IGF1-mediated survival rates to $20 \%(P<0.001$, one-way ANOVA), whereas BDNF-mediated survival rates remained unaffected $(P>0.05$, one-way ANOVA) (Fig. 2a). We then tested the phosphorylation of the IGF1R and downstream AKT with increasing IGF1 concentrations (Fig. 2b). We found maximal activation of the receptor and phosphorylation of downstream AKT with $20 \mathrm{ng} /$ ml IGF1 $(P<0.001$, one-way ANOVA) (Fig. $2 b-d)$. Addition of IGFBP5 $(200 \mathrm{ng} / \mathrm{ml})$ led to significant reduction of IGF1R $(P<0.05$, one-way ANOVA), and downstream AKT phosphorylation $(P<0.01$, one-way ANOVA), indicating that IGFBP5 is inhibitory for IGF1R activation and survival in cultures of isolated motoneurons (Fig. 2b-d). Similar observations were made with sensory neurons from embryonic lumbar DRGs (Fig. 2e-g). IGFBP5 reduced IGF-mediated activation of the IGF1R $(P<0.05$, one-way ANOVA) and AKT $(P<0.05$, one-way ANOVA). AKT activation by NGF was not affected.

To study this effect on motoneurons and sensory neurons in vivo, we generated mice with neuron-specific overexpression of IGFBP5. An 8-kb fragment including the human $N F-L$ promoter, mouse Igfbp 5 cDNA, the polyA signal from pMC-Cre and exons $2-4$ of the $N F-L$ gene was injected into fertilized mouse eggs (for details see electronic supplementary Fig. A1, supplementary methods section). Real-time
RT-PCR analysis revealed that the levels of $I g f b p 5 \mathrm{mRNA}$ in the spinal cord of 6 months old Igfbp5 transgenic mice (Bp5 $t g+)$ were up-regulated 1.8-fold compared with controls $(P<0.001$, two-tailed Student's $t$ test) (Fig. 3a). Western blot analysis for IGFBP5 in the spinal cord, sciatic nerve and brain of 6-month-old Igfbp5 transgenic mice exhibited a fivefold IGFBP5 protein up-regulation in the sciatic nerve $(P<0.001$, two-tailed Student's $t$ test) (Fig. 3b, c), indicating that the IGFBP5 protein is anterogradely transported in axons. Isolated motoneurons from Igfbp5 transgenic embryos (E13.5) also showed increased IGFBP5 immunoreactivity in cell bodies and axons after 7 days in vitro (Fig. 3d). IGFBP5 was predominantly localized on the surface of these neurons. This correlates with previous data showing that IGFBP5 binds to the cell surface and the surrounding extracellular matrix [2]. Igfbp 5 transgenic motoneurons showed a different survival response to IGF1 than wild-type motoneurons. While survival of Igfbp5-overexpressing motoneurons was unchanged in the presence of BDNF ( $P>0.05$, one-way ANOVA), their survival was significantly reduced by $37 \%$ in the presence of IGF1 compared to wild-type motoneurons $(P<0.001$, one-way ANOVA) (Fig. 3e). When we compared the dose response for IGF1 on motoneuron survival in Igfbp 5 transgenic and wild-type motoneurons, a shift was observed $(0.2$ ng/ml IGF1; $P<0.05 ; 1 \mathrm{ng} / \mathrm{ml} \mathrm{IGF1;} P<0.001 ; 5 \mathrm{ng} / \mathrm{ml}$ IGF1; $P<0.001$; one-way ANOVA) (Fig. 4a), indicating that motoneurons overexpressing IGFBP5 need more IGF1 for their survival than non-transgenic motoneurons. This result provides further evidence that IGFBP5 inhibits IGF1 actions on motoneurons. We then compared the phosphorylation levels of IGF1R and downstream AKT in Igfbp5 transgenic motoneurons relative to wild-type controls. A strong reduction in IGF1R and AKT phosphorylation levels was observed in Igfbp5 transgenic motoneurons compared to controls (pIGF1R: $P<0.001$; pAKT: $P<0.01$, two-tailed Student's $t$ test) grown for 5 days with $5 \mathrm{ng} / \mathrm{ml}$ BDNF, then starved overnight and pulsed for 20 min with $20 \mathrm{ng} / \mathrm{ml}$ IGF1 (Fig. 4b-d). Motoneurons overexpressing IGFBP5 also exhibited reduced axon growth (Fig. 4e, f), when cultured with IGF1 at a concentration of $5 \mathrm{ng} / \mathrm{ml}(P<0.001$, one-way ANOVA). Axon growth was normal when these motoneurons were cultured with $5 \mathrm{ng} / \mathrm{ml}$ BDNF $(P>0.05$, one-way ANOVA), indicating that IGFBP5 not only reduces survival but also specifically inhibits the effects of IGF1 on axon growth.

\section{Neuronal IGFBP5 overexpression leads to impaired motor function, degeneration and loss of motor axons and cell bodies}

To test whether neuronal IGFBP5 overexpression reduces responsiveness to endogenous IGF1, we immunoprecipitated the IGF1R from the spinal cord and sciatic nerve of 4-day-old Igfbp5 transgenic mice, a time period when 
Fig. 2 IGFBP5 decreases the survival promoting downstream effect of IGF1 on isolated wildtype motoneurons. a IGFBP5 (BP5) reduced IGF1-mediated survival effects from 43 to $20 \%$ on wild-type motoneurons after 7 days in culture, while IGFBP5 did not inhibit BDNF-mediated survival. b Downstream activation of IGF1 signaling pathway in wild-type motoneurons after stimulation with different IGF1 concentrations. Wild-type motoneuron cell cultures were grown for 5 days with $5 \mathrm{ng} / \mathrm{ml}$ BDNF, starved overnight and pulsed for $20 \mathrm{~min}$ with indicated IGF1 concentrations. Western blot analyses revealed the strongest phosphorylation of IGF1R (b, c) and AKT (b, d) with $20 \mathrm{ng} / \mathrm{ml}$ IGF1. e Downstream activation of IGF1 signaling pathway in wild-type DRGs after stimulation with IGF1. Wild-type DRG cell cultures were grown for $20 \mathrm{~h}$ with $10 \mathrm{ng} / \mathrm{ml} \mathrm{NGF}$, starved for $4 \mathrm{~h}$ and pulsed for 20 min with indicated factors. Western blot analyses revealed the strongest phosphorylation of IGF1R $(\mathbf{e}, \mathbf{f})$ and AKT $(\mathbf{e}, \mathbf{g})$ with $20 \mathrm{ng} / \mathrm{ml} \mathrm{IGF1}$ a

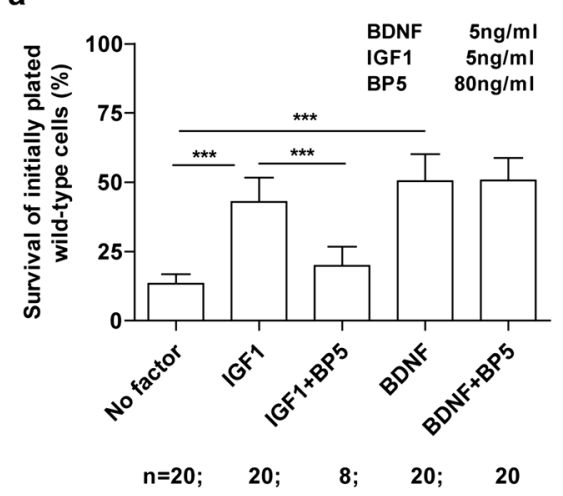

c

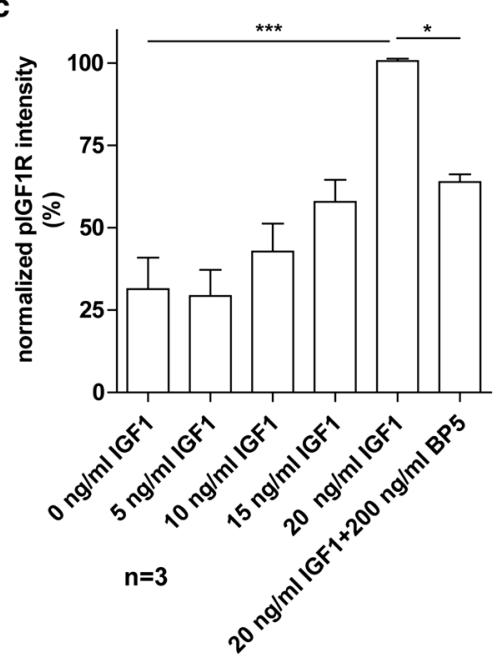

b

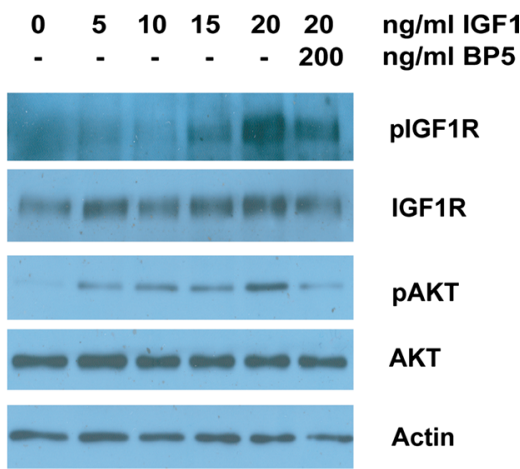

e

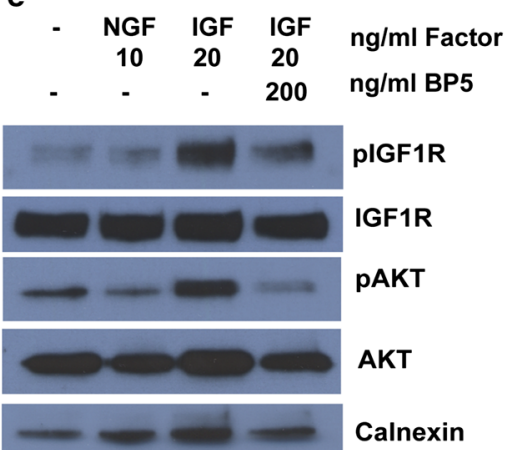

d

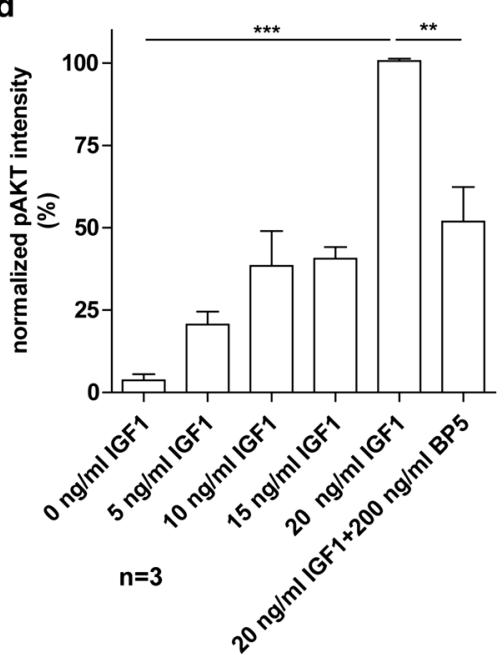

f

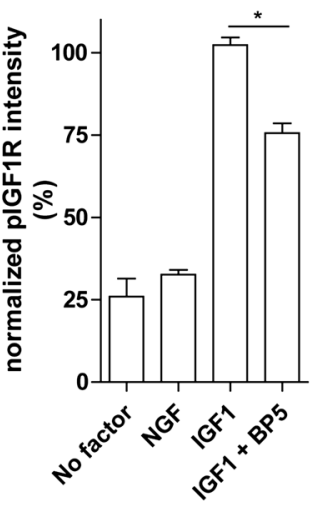

$n=3$ g

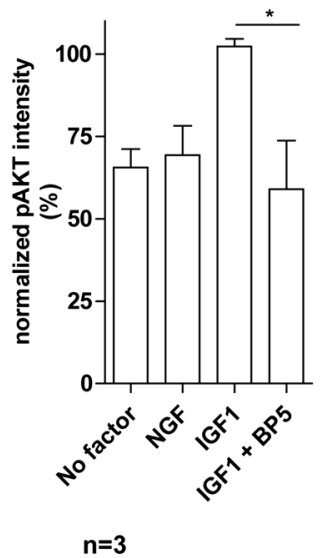

endogenous IGF1 levels are high. Analyses of spinal cord and sciatic nerve extracts by Western blot with a specific pIGF1R antibody revealed a significant $35 \%$ reduction in the phosphorylation of the IGF1R $(P<0.01$, two-tailed Student's $t$ test) (Fig. 5a, b). Elevated IGFBP5 immunoreactivity was observed in axons of the sciatic nerve and the extracellular matrix of $I g f b p 5$ transgenic mice (see arrows in Fig. 5c), closely resembling the distribution of IGFBP5 in sural nerve biopsies of patients with DNP (Fig. 1d).

Next, we investigated the morphology of peripheral nerves. The number of sciatic nerve axons in Igfbp 5 transgenic mice was reduced by $14 \%$ when compared to wild-type animals at 6 months of age $(P<0.05$, twotailed Student's $t$ test) (Figs. 5e, 6b, c [arrows indicate 
Fig. 3 Igfbp5 $t g+$ motoneurons show decreased survival when cultured with IGF1. a qRT-PCR revealed a 1.8 -fold increase of the Igfbp5 mRNA level in the spinal cord of 6-month-old Igfbp5 $t g+$ mice (Bp5 tg+). Scored values were obtained by normalizing to $\beta$-actin mRNA levels. A.U. arbitrary units. b Igfbp5 protein elevation was detected in sciatic nerve, but not in spinal cord and brain of 6-month-old Igfbp5 $t g+$ mice compared to controls. Actin was used as loading control. c Quantification of Igfbp5 protein levels. $Q L$ quantitative labeling. d Motoneurons stained for Tau (red) and Igfbp5 (green) 7 days after plating. Igfbp5 was increased in the soma and neurites of $I g f b p 5 t g+$ motoneurons. Igfbp5 appeared associated with the cell membrane. Scale bar $5 \mu \mathrm{m}$. e The positive effect of IGF1 on motoneuron survival is reduced by $37 \%$ in Igfbp5 tg + motoneurons. Motoneuron survival was unchanged in the presence of BDNF
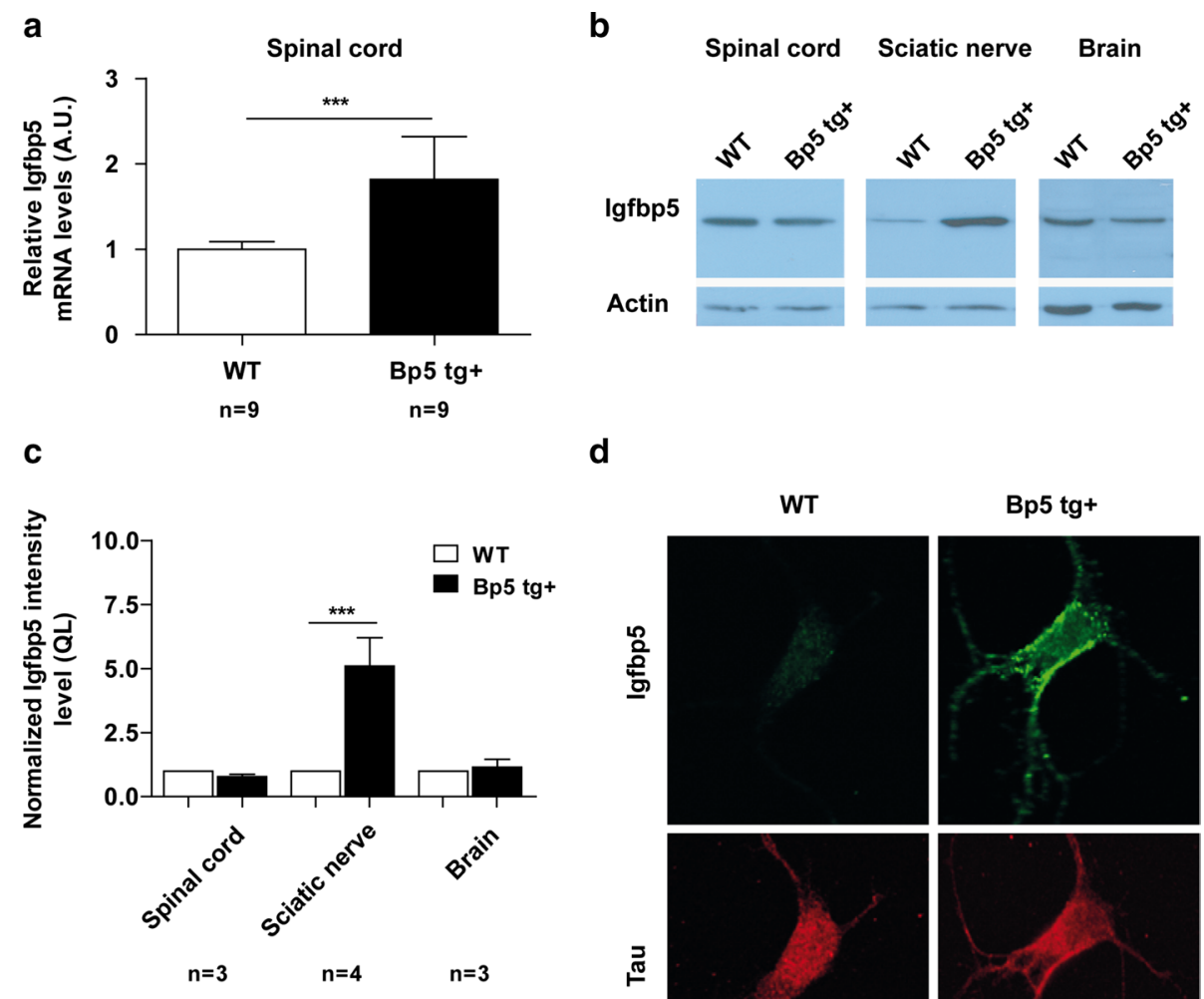

d
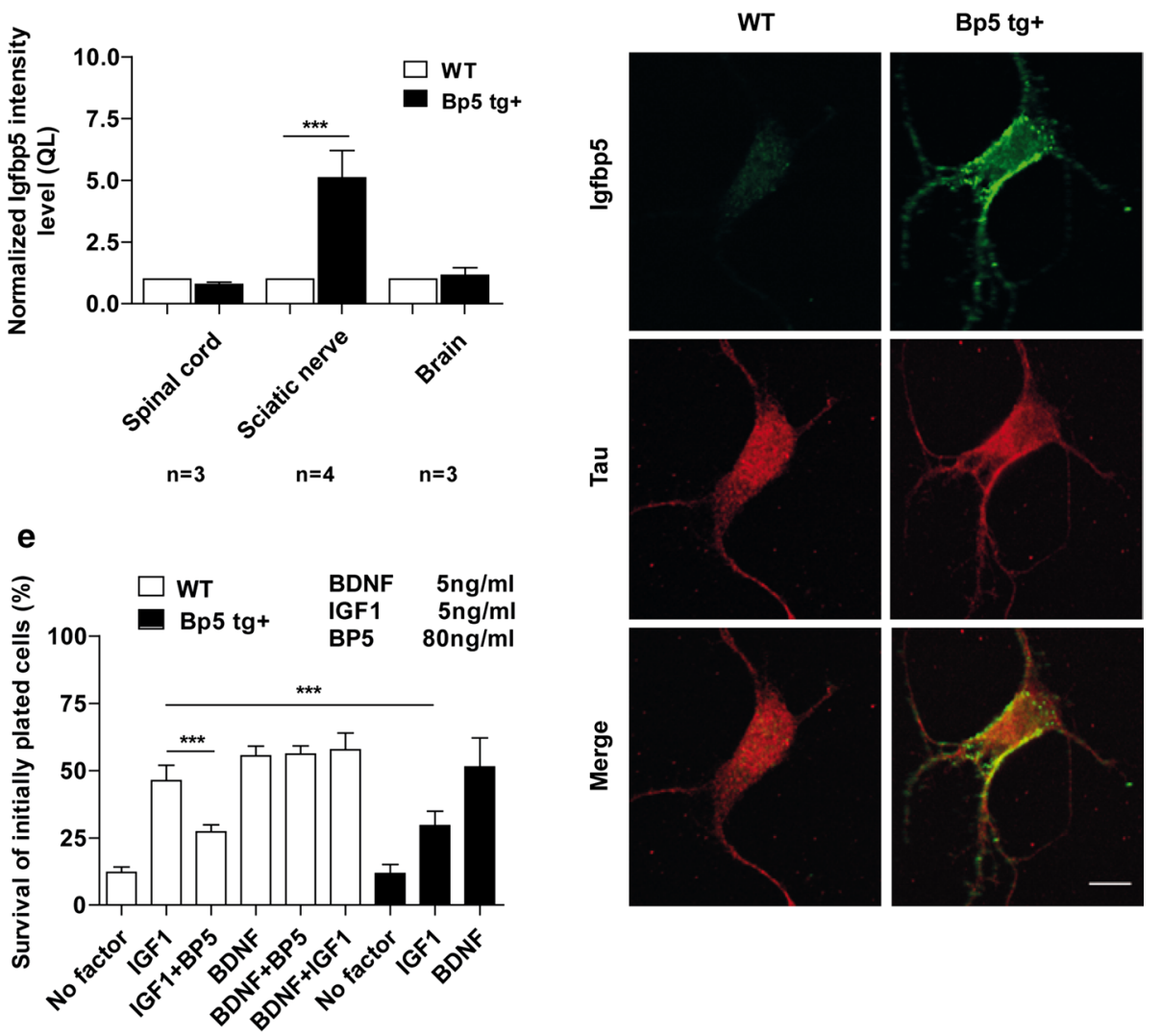

$n=16 ; 16 ; 12 ; 16 ; 12 ; 16 ; 20 ; 20 ; 20$

degenerating axons], electronic supplementary Table A3). In parallel, a change in fiber size distribution in the sciatic nerve became apparent, with a significant reduction of fibers with a circumference between 20-25 $\mu \mathrm{m}$ in IGFBP5-overexpressing mice $(P<0.01$, two-way ANOVA) (Fig. 5f). In addition, the M-ratio was significantly reduced by $20 \%$ in transgenic animals $(P<0.05$, two-tailed Student's $t$ test) (Fig. 5d, g). Quantification of myelinated axons in the phrenic nerve of 3-week-old Igfbp 5 transgenic mice revealed a significant axonal loss of $15 \%(P<0.01$, two-tailed Student's $t$ test) (Fig. 6e; electronic supplementary Table A3). No further loss of phrenic nerve fibers was detected in 5- to 6-month-old Igfbp 5 transgenic mice (electronic supplementary Table
A3; Fig. 6a). These data suggest that local inhibition of IGF1 not only affects motor axons but also the degree of myelination in Schwann cells. To determine whether axon degeneration and axon loss reflected loss of motoneuron cell bodies, we also counted motoneurons in the facial nucleus and the lumbar spinal cord of wild-type and Igfbp 5 transgenic mice at different stages of postnatal development. In newborn and 3-week-old animals (Fig. 6f), numbers of facial motoneurons were not significantly different between wild-type and Igfbp 5 transgenic mice $(P>0.05$, one-way ANOVA) (electronic supplementary Table A3), indicating that neuronal IGFBP5 overexpression has no effect on the generation and developmental cell death of motoneurons. However, by 


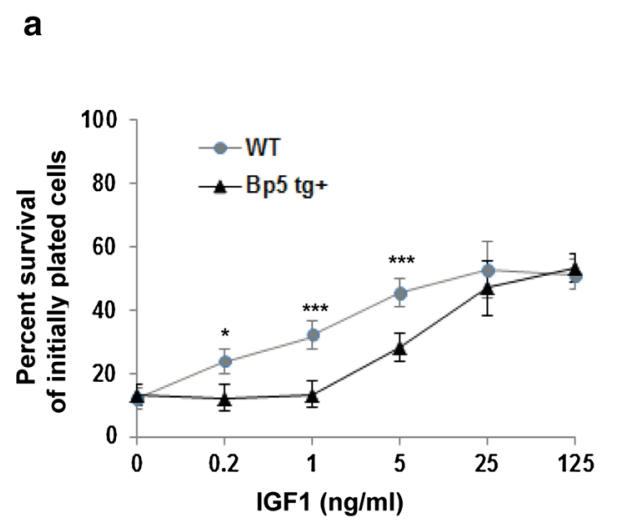

b

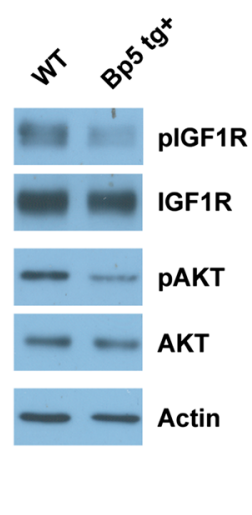

C

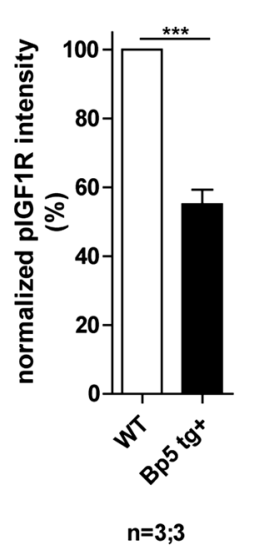

d

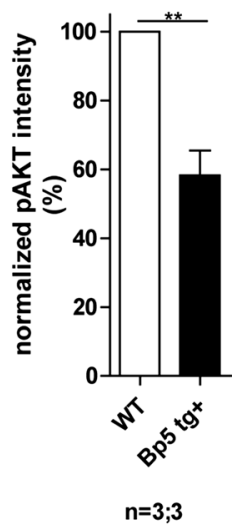

e
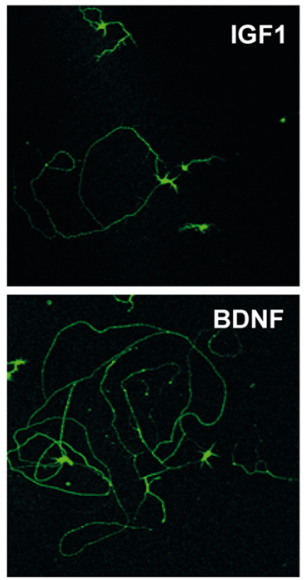
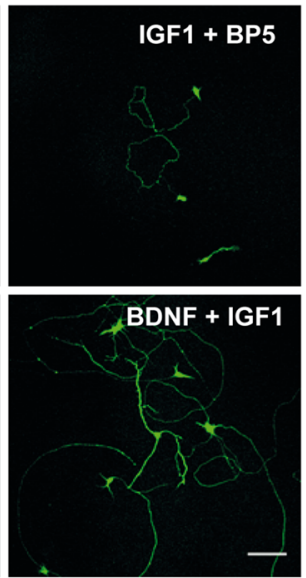

Fig. 4 Reduced phosphorylation of IGF1 receptor in Igfp5 tg+ motoneurons leads to reduced survival and axon outgrowth. a Doseresponse curve for IGF1-mediated motoneuron survival. Wild-type and Igfp $5 t g+$ motoneurons (7 DIV) were treated with different IGF1 concentrations. b Reduced phosphorylation of IGF1 receptor and AKT in Igfbp5 tg+ motoneurons compared to wild-type motoneurons. c Quantification of pIGF1R protein levels in motoneurons. d

5-6 months of age, a $17 \%$ loss of facial motoneurons became apparent $(P<0.01$, one-way ANOVA) (Fig. 6f; electronic supplementary Table A3). In the spinal cord, no significant loss of motoneurons could be observed at 4 months of age ( $P>0.05$, one-way ANOVA). In contrast, at 5-6 months, a $20 \%$ loss of motoneurons was observed $(P<0.001$, one-way ANOVA) (Fig. 6g, electronic supplementary Table A3) and remaining spinal motoneurons exhibited signs of atrophy (Fig. 6d, indicated by white arrows). At 16 months, the level of motoneuron loss remained at $20 \%$, indicating that spinal motoneuron loss was maximal by $5-6$ months and did not progress thereafter $(P<0.05$, one-way ANOVA) (Fig. $6 \mathrm{~g}$; electronic supplementary Table A3). Nine-month-old

f
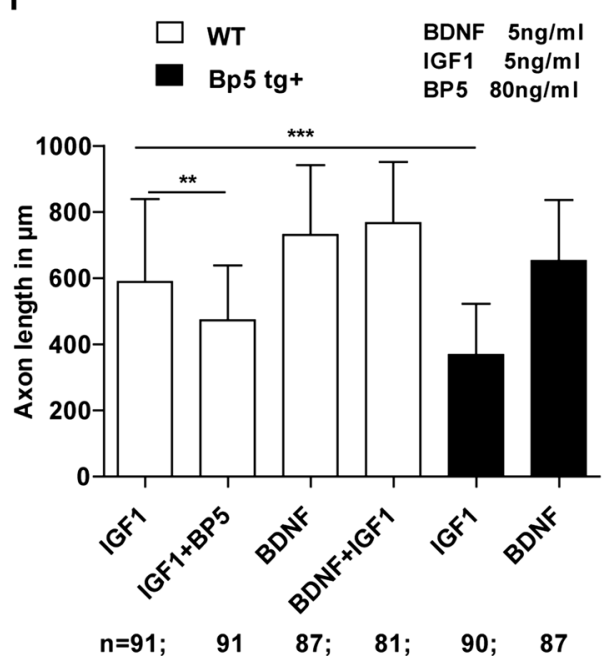

Quantification of pAKT protein levels in motoneurons. e Images of cultured wild-type motoneurons stained against Tau to identify axons. Scale bar $100 \mu \mathrm{m}$. f Igfbp5 (BP5) inhibited IGF1-induced axon outgrowth in wild-type motoneurons. Igfbp5 $t g+$ motoneurons showed shorter axons than wild-type axons when cultured with IGF1. Axon growth stimulated by BDNF was not affected in Igfbp $5 \mathrm{tg}+$ motoneurons

Igfbp5 transgenic mice showed a significant reduction of forelimb grip strength $(P<0.001$, one-way ANOVA) (Fig. 6h). In 5- to 6-month-old Igfbp5 transgenic mice, nerve conduction studies of the sciatic nerve $[6,29$, 57] revealed that motor nerve conduction velocities (M-NCVs) were reduced by $18 \%$ when compared to controls $(P<0.05$; two-tailed Student's $t$ test) (Fig. 6i), which is compatible with a mild, putatively secondary demyelinating component of the neuropathy. Amplitudes of distal compound muscle action potentials (CMAPs) and compound sensory-motor nerve conduction velocities (cSNCVs) were not significantly altered $(P>0.05$; two-tailed Student's $t$ test) (Fig. 6j, k; electronic supplementary Fig. A1). 
Fig. 5 IGFBP5-overexpressing mice show decreased activation of IGF1 receptor that corresponds to motoneuron degeneration and myelination defects. a, b Immunoprecipitation of the IGF1 receptor from spinal cord (left panel) and sciatic nerve (right panel) extracts of 4-day-old mice and subsequent analysis of phosphorylation showed decreased activation levels in Igfbp5 tg+ mice compared to controls. $S N$ supernatant, IP immunoprecipitation. c Localization of Igfbp5 in cross sections of sciatic nerves. Igfbp5 was increased in axons and extracellular matrix of Igfbp $5 \mathrm{tg}+$ mice. Arrows depict extracellular matrix staining. Scale bar $5 \mu \mathrm{m}$. d Representative photomicrograph of myelinated fibers in semithin cross sections of the sciatic nerve of 6-month-old wild-type and $I g f b p 5 t g+$ animals. Scale bar $10 \mu \mathrm{m}$. e 5- to 6-month-old Igfbp $5 \mathrm{tg}+$ mice showed a $14 \%$ loss of sciatic nerve fibers. f The frequency of fibers with a circumference between 20-25 $\mu \mathrm{m}$ was decreased by $4.5 \%$ in the sciatic nerve of 6-month-old Igfbp5 tg + mice. $g$ The M-ratio was significantly reduced by $20 \%$ in 6-month-old Igfbp5 $\operatorname{tg}+$ mice a
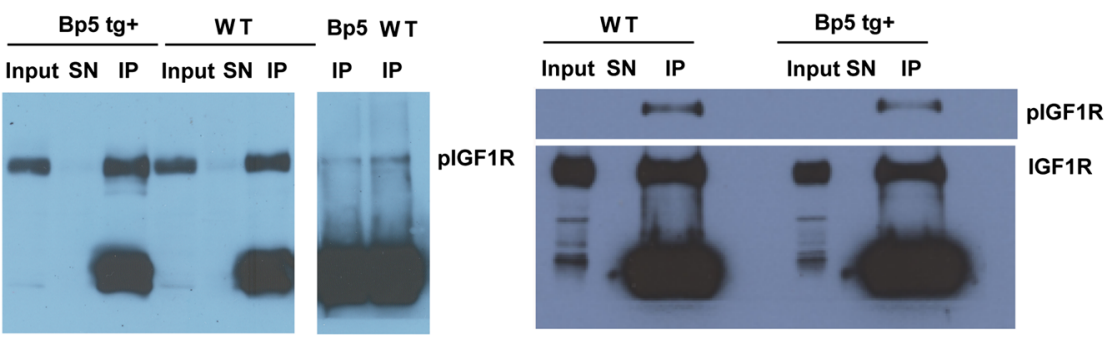

b
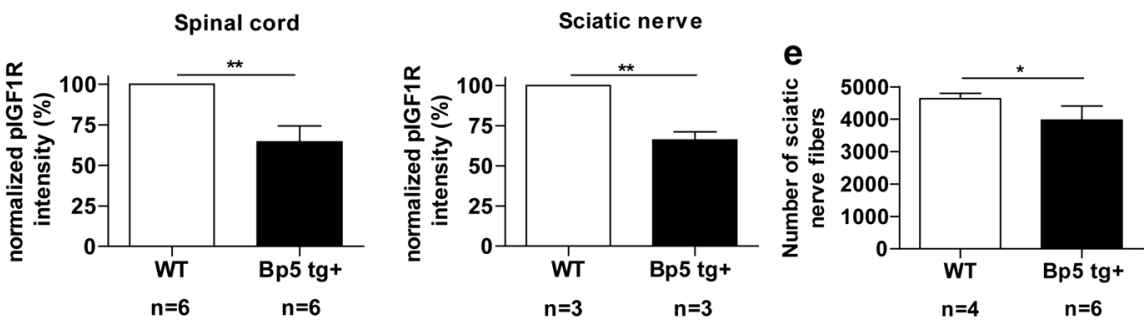

c

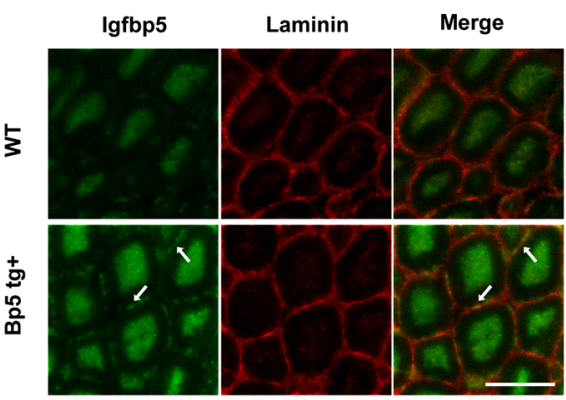

f

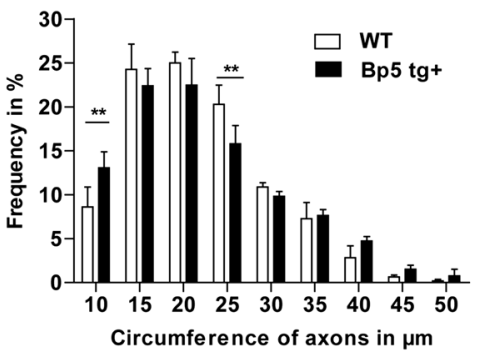

d
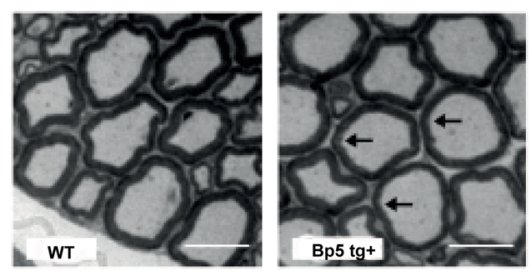

9

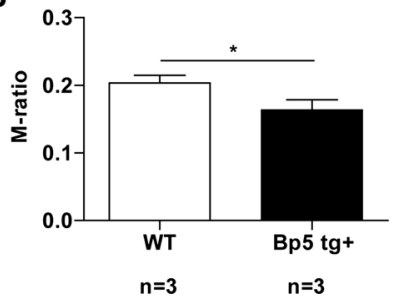

\section{Sensory defects in Igfbp5 transgenic mice}

Since sensory defects are a hallmark of diabetic neuropathy, we studied a sensory nerve (saphenous nerve) in IGFBP5overexpressing mice in more detail and also tested behavioral parameters of sensory function. The gross overall morphology of the saphenous nerve appeared unaltered in 10-11 monthold Igfbp 5 transgenic mice compared with that of age-matched wild-type mice (electronic supplementary Fig. A2). Nevertheless, 10-11 month-old Igfbp5 transgenic mice demonstrated a higher withdrawal threshold in the von Frey hair stimulation test $(P<0.01$, two-tailed Student's $t$ test) and thermal hypoalgesia test as illustrated by longer withdrawal latencies to a noxious heat stimulus in the Hargreaves test $(P<0.001$, twotailed Student's $t$ test) (electronic supplementary Fig. A3). This indicates that sensory neurons are also affected in Igfbp 5 transgenic mice. In addition, deficits in coordination and balance were revealed on an accelerating rotarod. 9-Month-old Igfbp5 transgenic mice fell from the device in significantly less time than control animals $(P<0.001$, one-way ANOVA) (electronic supplementary Fig. A3), whereas younger 2-month-old mice did not show any deficits in this test.

In the glabrous footpad skin, almost all nerve fibers in the epidermis are unmyelinated free nerve endings [58] and can be visualized using the pan-neuronal marker PGP9.5. The density of PGP9.5-positive fibers which passed through the basement membrane of the epidermis appeared significantly reduced in 10-month-old Igfbp 5 transgenic mice $(P<0.01$, two-tailed Student's $t$ test) (electronic supplementary Fig. A3). In line with this observation, reduced substance P levels were found in the footpad of 10-monthold Igfbp 5 transgenic mice compared with control animals $(P<0.05$, two-tailed Student's $t$ test) (electronic supplementary Fig. A3). 
Fig. 6 Nerve fiber degeneration and spinal motoneuron loss are partly reflected in electrophysiological alterations in motor nerves of Igfbp 5 transgenic mice. a Light micrographs of 6-month-old wild-type, Igfbp5 tg + and cIgflr ko phrenic nerve semithin sections stained with azur-methylene blue. Scale bar $20 \mu \mathrm{m}$. b, c Sciatic nerve cross sections of wild-type and $I g f b p 5 t g+$ mice. No degenerating fibers were detectable in control tissue and small fibers appeared normal in Igfbp5 tg+ mice. Larger fibers of 6-monthold wild-type and Igfbp5 tg+ mice (arrows) showed signs of degeneration. Scale bar $10 \mu \mathrm{m}$. d Nissl-stained paraffin sections of the lumbar spinal cord showed degenerating motoneurons in $I g f b p 5 t g+$ mice compared to wild-type animals. Scale bar $50 \mu \mathrm{m}$. e 3-week-old Igfbp $5 \mathrm{tg}+$ mice showed a $15 \%$ loss of phrenic nerve axons. f, g In 5- to 6-month-old Igfbp5 $t g+$ mice, the number of facial motoneurons was reduced by $17 \%$, and the number of lumbar spinal motoneurons by $20 \%$. h 9-Month-old Igfbp5 $t g+$ mice showed reduced grip strength compared with wild-type animals. i Motor nerve conduction velocity (M-NCV) was reduced significantly in Igfbp $5 \mathrm{tg}+$ mice by $18 \%$ in sciatic nerve. $\mathbf{j}$ Distal compound muscle action potential (CMAP) amplitudes were not altered in $I g f b p 5 t g+$ and control animals. $\mathbf{k}$ Compound sensory-motor nerve conduction velocity (cSNCV) was not altered in Igfbp $5 \mathrm{tg}+$ mice a

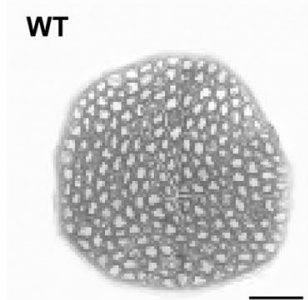

Bp5 tg+

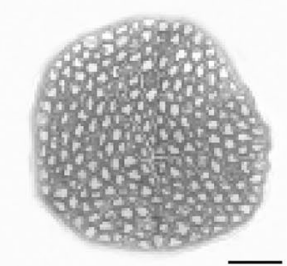

clgf1r ko

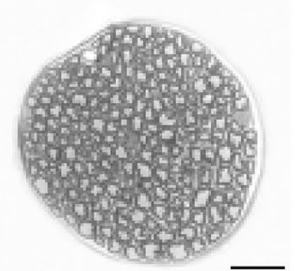

e

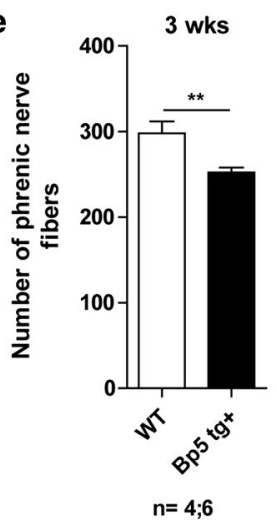

h

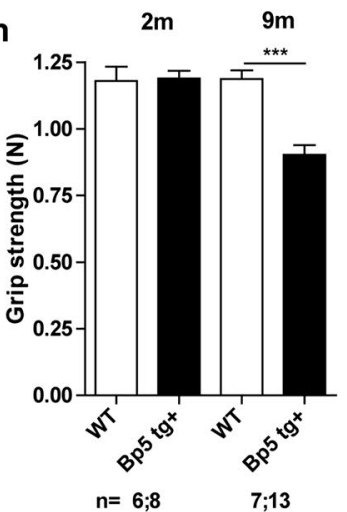

b

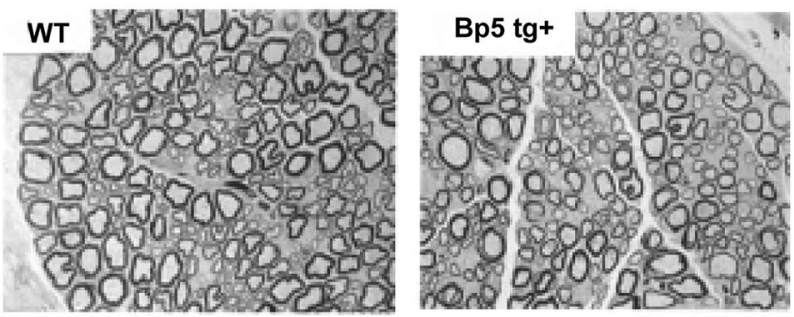

C
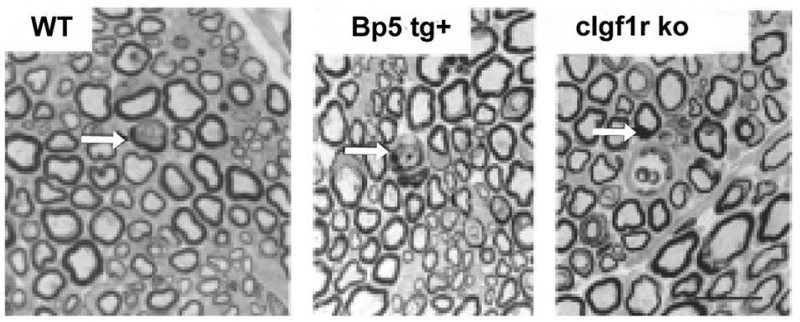

d
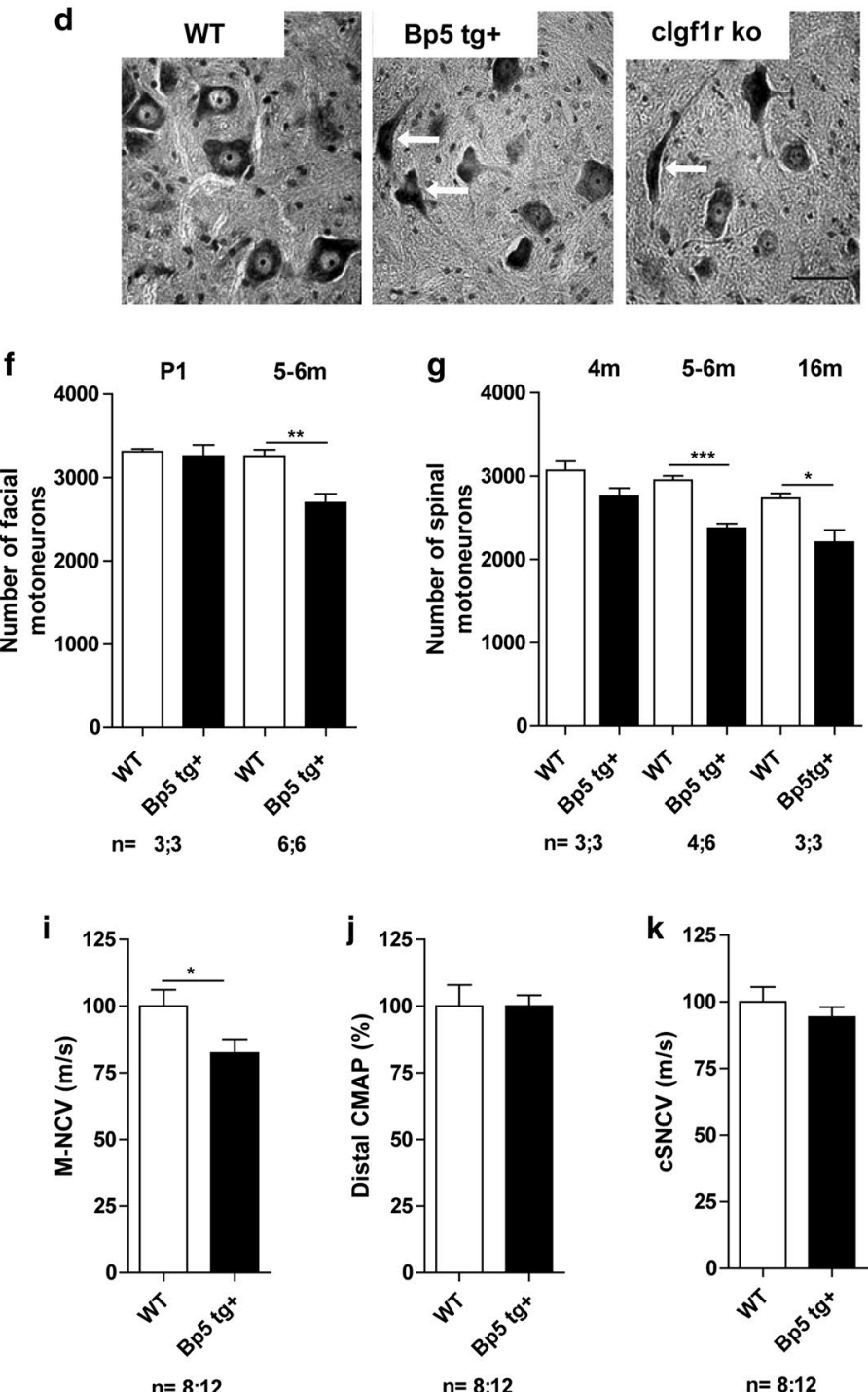

$n=8 ; 12$ 


\section{Conditional deletion of IGF1 receptor in neurons results in axonopathy and motoneuron loss similar to that seen with IGFBP5 overexpression}

To investigate whether degeneration of motoneurons in Igfbp 5 transgenic mice is caused primarily by the reduced availability of IGF1 for axons, or whether this is secondary to effects on Schwann cells, we analyzed mice lacking the type 1 IGF receptor in neurons ( $c I g f l r k o$ ). For this purpose, mice carrying loxP sites flanking exon III of the mouse Igflr gene were generated (for details see electronic supplementary Fig. A4; supplementary methods section). Exon III encodes most of the cysteine-rich ligand-binding domain of the $\alpha$-subunit of the receptor, and disruption of this exon generates an inactive receptor [30]. The Cre recombinase is controlled by the NF-L promoter which has been shown to be highly selective for neurons [41]. Neuronspecific disruption of exon III was confirmed by RT-PCR (electronic supplementary Fig. A4). Immunoprecipitation of the IGF1R from spinal cord of 4-day-old cIgflr ko mice revealed a $32 \%$ reduction in IGF1R phosphorylation in the spinal cord (electronic supplementary Fig. A4). Histological analysis of the sciatic nerve of cIgflr ko mice revealed a $13 \%$ reduction of nerve fibers at 6 months $(P<0.05$; two-tailed Student's $t$ test) (Fig. 6c; electronic supplementary Fig. A4, electronic supplementary Table A4). As found in IGFBP5-overexpressing mice, cIgflr ko mice showed a decrease of $6 \%$ in fibers with a circumference between 20-25 $\mu \mathrm{m}(P<0.05$, two-way ANOVA) (electronic supplementary Fig. A4). As expected, the M-ratio was normal $(P>0.05$, two-tailed Student's $t$ test) (electronic supplementary Fig. A4), because IGF1 signaling in Schwann cells was unaffected by neuron-specific inactivation of the mouse Igflr gene. The number of myelinated axons was also reduced by $11 \%$ in the phrenic nerve of cIgflr ko mice $(P<0.05$, two-tailed Student's $t$ test) (Fig. 6a; electronic Table A4). In 9-month-old cIgflr ko mice, a significant reduction of motoneurons by $16 \%$ was observed in the facial nuclei $(P<0.05$, two-tailed Student's $t$ test $)$ and by $21 \%$ in the lumbar spinal cord $(P<0.01$, two-tailed Student's $t$ test) compared to controls, an effect that was not observed in newborn mice (electronic supplementary Fig. A5 and Table A4). In addition, atrophic and degenerating motoneurons were frequently found in the spinal cord (Fig. 6d, indicated by white arrows). We then investigated potential electrophysiological alterations. Comparison of wild-type and cIgflr ko mice revealed that distal compound motor action potentials (CMAPs), motor nerve conduction velocities (M-NCVs) and compound sensory-motor nerve conduction velocities (cSNCVs) were not significantly reduced in cIgflr ko mice ( $P>0.05$, two-tailed Student's $t$ test) (electronic supplementary Fig. A5). A mild abnormality, namely increased dispersion in the F-waves (late responses traveling to and returning from the anterior horn cells along the entire length of the peripheral nerve fibers), was observed $(P<0.05$, two-tailed Student's $t$ test) (electronic supplementary Fig. A5). This finding may be an indicator that some $\mathrm{F}$-wave generating individual nerve fibers display minor conduction abnormalities at some level along their axons. These changes are compatible with, but not specific for, a mild axonal pathology $[21,57]$ and resemble features found in some patients with very early DNP [36, 48].

\section{Discussion}

Here, we show that IGFBP5 is more than 7-fold up-regulated at the mRNA level and at least 5-fold at the protein level in diabetic nerves compared to nerves from CIDP individuals and 50-fold compared to nerves from non-diabetic control individuals suggesting a pathogenic role of IGFBP5 in diabetic neuropathy. IGFBP5 is mainly found in axons and within the extracellular matrix surrounding the axons, indicating that it is produced in motoneurons, anterogradely transported and released into the extracellular space. Thus, it could interfere with the signaling of IGF1 derived both from the circulation and from contacting Schwann cells. Both Schwann cells and axons express IGF1 receptors, and altered IGF1 responses therefore could affect both axon and Schwann cell integrity. To test this hypothesis, two new mouse models were generated, with overexpression of IGFBP5 in motoneurons, and specific ablation of the IGF1R in the same population of cells. Our results show that elevated IGFBP5 protein levels and reduced IGF1 signaling in peripheral nerves are important factors contributing to progressive loss of motor fibers and subsequent loss of motoneurons, and they are also associated with classical signs of diabetic neuropathy such as altered thresholds for heat, pain and mechanosensation. Previous studies have reported reduced levels of circulating IGF1 as a common feature in diabetes, with the highest reductions seen at older ages and with longer duration of disease [47]. Similarly, in the streptozotocin-induced rat model, reduced IGF1 expression in peripheral nerves is observed at early stages of disease [53]. Our data indicate that additional components of IGF1 signaling are dysregulated in the peripheral nervous system. The IGF1R that mediates the trophic effects of IGF1 on Schwann cells and neurons is up-regulated in nerve biopsies from patients, as is IGFBP5, an IGF1-binding protein that inhibits IGF1-mediated survival and axon growth in motoneurons. IGF1 depletion in mice leads to a broad range of defects in the brain, with hypomyelination and loss of some neuronal populations in the CNS [3]. These mice die by about 2 months of age. Postnatally, they do not exhibit any significant loss of motoneuron cell bodies at early stages, indicating that motoneuron development during embryogenesis does not depend 
on IGF1. Similarly, mice overexpressing IGFBP5 appear normal at birth and at younger ages; however, by 6 months of age, prominent dysmyelination occurs. Similarly, the loss of motor fibers and motoneuron cell bodies was not detectable until 6 months of age, a stage that IGF1-deficient mice do not reach [3]. Interestingly, dysmyelination was not observed in cIgflr $k o$ mice, indicating that the observed defects in peripheral nerve myelination in IGFBP5-overexpressing mice are likely to be due to reduced IGF1 function in Schwann cells. These conditional IGF1R deletion mutants further revealed that axon maintenance is directly dependent on IGF1R activation, since loss of large motor fibers in the phrenic, facial, and the mixed sciatic nerve was observed in the clgflr ko mice. Sensory axons appeared affected too, reflected by altered responses to heat and mechanical stimulation in Igfbp5 transgenic animals. Furthermore, Igfbp5 transgenic mice show reduced latency to fall from an accelerating rotarod, pointing to the involvement of proprioceptive neurons. Together with the altered thresholds for heat-sensing thermoreceptors, reduced substance $\mathrm{P}$ levels and reduced density of small fibers in the skin, this resembles classical signs of diabetic neuropathy, which affects both sensory neurons and motor neurons, the last named predominantly at later stages. Thus, the reduced availability of IGF1 coupled with elevated expression of IGFBP5 in diabetic nerves would be predicted to have a major effect on myelination and trophic support of axons.

Up-regulation of IGFBP5 has also been observed in other organs in diabetes. The mechanisms are not clear. It has been suggested that the IGFBP5 up-regulation is induced by elevated glucose [43] and reduced insulin signaling. It could reflect a condition in diabetes under which cells protect themselves against signals for growth and mitosis when they are metabolically dysregulated. IGF1 is a potent growth factor which mediates the cellular effects of growth hormone, but it also regulates maintenance and dynamics of axon growth [7,8], and therefore the neuronal up-regulation of IGFBP5 which appears as a protective mechanism to prevent cell growth under the metabolic conditions of diabetes also prevents the IGF-1 signaling from Schwann cells which is necessary for axon stability, axon dynamics and excitability of sensory neurons [51]. In diabetic rats, IGFBP5 mRNA upregulation has been observed in the kidney $[9,35]$, suggesting that elevated IGFBP5 expression levels could contribute to kidney dysfunction during the course of diabetes. Cell cultures of cardiac fibroblasts react to elevated glucose with upregulation of IGFBP5 protein levels, which lead to increased c-Jun N-terminal kinase phosphorylation and induction of apoptosis in cardiomyocytes [43]. This mechanism could contribute to deterioration of heart function in diabetes. Furthermore, elevated protein levels of IGFBP5 and reduced protein levels of IGF1 are found in young patients with type I diabetes showing decreased bone mass [32]. Increased levels of IGFBP5 correlate with defects in microvascular endothelial cells in retina and kidney [17], and it has been proposed that these defects could be mediated through altered response of these cells to IGF1. Our data showing that IGF1R activation is reduced in peripheral nerves from mice overexpressing IGFBP5, and that mice lacking IGF1R signaling in motoneurons show similar signs of motor neuropathy as IGFBP5-overexpressing mice strongly suggest that the up-regulation of IGFBP5 is also responsible for microangiopathy, heart failure, kidney failure, reduced bone mass and other pathological findings associated with diabetes.

Our data from mouse models suggest that inhibiting the up-regulation of IGFBP5 expression in peripheral nerves might prevent or slow down disease progression. Similarly, inhibitors of IGFBP5 that block binding to IGF1 could be of therapeutic benefit. As shown by X-ray crystallography [56], the domains of IGF1 that bind to IGFBP5 are different from those that bind to the receptor. Thus, it should be feasible to discover inhibitors that prevent the interaction of IGF1 with IGFBP5, but not with the IGF1 receptor. Such molecules could not only prevent the loss of motor axons and motor function, but also the loss of myelinated sensory axons and thus would open new strategies for testing in prospective clinical trials for DNP.

Acknowledgments We thank Katrin Walter, Simone Rink, Manuela Kohles, Christian Mehling, Lydia Biko and Regine Sendtner for technical assistance and Robert Blum for help on the confocal microscope. This work was supported by the DFG, Grant SFB 581, TP B4, the Graduate School of Life Sciences, University of Wuerzburg, the European Community's Health Seventh Framework Programme under Grant agreement 259867 (EuroMOTOR), the German Government (BMBF) funded Motoneuron Disease Network, The Sobek Foundation, and the Hermann und Lilly Schilling-Stiftung im Stifterverband der Deutschen Industrie. The authors have no financial interests.

Compliance with ethical standards All procedures performed in studies involving human participants were in accordance with the ethical standards of the institutional and/or national research committee and with the 1964 Helsinki declaration and its later amendments or comparable ethical standards. Informed consent was obtained from all individual participants included in the study. All procedures performed in studies involving animals were in accordance with the ethical standards of the institution or practice at which the studies were conducted.

Open Access This article is distributed under the terms of the Creative Commons Attribution 4.0 International License (http://creativecommons.org/licenses/by/4.0/), which permits unrestricted use, distribution, and reproduction in any medium, provided you give appropriate credit to the original author(s) and the source, provide a link to the Creative Commons license, and indicate if changes were made.

\section{References}

1. Bach LA, Headey SJ, Norton RS (2005) IGF-binding proteins-the pieces are falling into place. Trends Endocrinol Metab 16:228-234. doi:10.1016/j.tem.2005.05.005 
2. Beattie J, Allan GJ, Lochrie JD, Flint DJ (2006) Insulin-like growth factor-binding protein-5 (IGFBP-5): a critical member of the IGF axis. Biochem J 395:1-19. doi:10.1042/BJ20060086

3. Beck KD, Powell-Braxton L, Widmer HR, Valverde J, Hefti F (1995) Igf1 gene disruption results in reduced brain size, CNS hypomyelination, and loss of hippocampal granule and striatal parvalbumin-containing neurons. Neuron 14:717-730

4. Bondy C, Lee WH (1993) Correlation between insulin-like growth factor (IGF)-binding protein 5 and IGF-I gene expression during brain development. J Neurosci 13:5092-5104

5. Boulton AJ, Ward JD (1986) Diabetic neuropathies and pain. Clin Endocrinol Metab 15:917-931

6. Bremer J, Baumann F, Tiberi C, Wessig C, Fischer H, Schwarz P, Steele AD, Toyka KV, Nave KA, Weis J et al (2010) Axonal prion protein is required for peripheral myelin maintenance. Nat Neurosci 13:310-318. doi:10.1038/nn.2483

7. Caroni P (1993) Activity-sensitive signaling by muscle-derived insulin-like growth factors in the developing and regenerating neuromuscular system. Ann N Y Acad Sci 692:209-222

8. Caroni P, Grandes P (1990) Nerve sprouting in innervated adult skeletal muscle induced by exposure to elevated levels of insulin-like growth factors. J Cell Biol 110:1307-1317

9. Carson MJ, Behringer RR, Brinster RL, McMorris FA (1993) Insulinlike growth factor I increases brain growth and central nervous system myelination in transgenic mice. Neuron 10:729-740

10. Cheng HL, Randolph A, Yee D, Delafontaine P, Tennekoon G, Feldman EL (1996) Characterization of insulin-like growth factor-I and its receptor and binding proteins in transected nerves and cultured Schwann cells. J Neurochem 66:525-536

11. Cheng HL, Russell JW, Feldman EL (1999) IGF-I promotes peripheral nervous system myelination. Ann N Y Acad Sci 883:124-130

12. Cheng HL, Sullivan KA, Feldman EL (1996) Immunohistochemical localization of insulin-like growth factor binding protein-5 in the developing rat nervous system. Brain Res Dev Brain Res 92:211-218

13. Clemmons DR (1997) Insulin-like growth factor binding proteins and their role in controlling IGF actions. Cytokine Growth Factor Rev 8:45-62

14. Clemmons DR, Jones JI, Busby WH, Wright G (1993) Role of insulin-like growth factor binding proteins in modifying IGF actions. Ann N Y Acad Sci 692:10-21

15. Drop SL, Schuller AG, Lindenbergh-Kortleve DJ, Groffen C, Brinkman A, Zwarthoff EC (1992) Structural aspects of the IGFBP family. Growth Regul 2:69-79

16. Fressinaud C, Jean I, Dubas F (2003) Selective decrease in axonal nerve growth factor and insulin-like growth factor I immunoreactivity in axonopathies of unknown etiology. Acta Neuropathol 105:477-483. doi:10.1007/s00401-002-0669-7

17. Giannini S, Cresci B, Manuelli C, Pala L, Rotella CM (2006) Diabetic microangiopathy: IGFBP control endothelial cell growth by a common mechanism in spite of their species specificity and tissue peculiarity. J Endocrinol Invest 29:754-763

18. Gundersen HJ (1978) Estimators of the number of objects per area unbiased by edge effects. Microsc Acta 81:107-117

19. Hughes R, Bensa S, Willison H, Van den Bergh P, Comi G, Illa I, Nobile-Orazio E, van Doorn P, Dalakas M, Bojar M et al (2001) Randomized controlled trial of intravenous immunoglobulin versus oral prednisolone in chronic inflammatory demyelinating polyradiculoneuropathy. Ann Neurol 50:195-201

20. Hughes RA, Sendtner M, Thoenen H (1993) Members of several gene families influence survival of rat motoneurons in vitro and in vivo. J Neurosci Res 36:663-671. doi:10.1002/jnr.490360607

21. Kimura J (2001) Principles and variations of nerve conduction studies, and techniques to assess muscle function. In: Electrodiagnosis in diseases of nerve and muscle: principles and practice. Oxford University Press, New York, pp 91-117

22. Jablonka S, Karle K, Sandner B, Andreassi C, von Au K, Sendtner M (2006) Distinct and overlapping alterations in motor and sensory neurons in a mouse model of spinal muscular atrophy. Hum Mol Genet 15:511-518. doi:10.1093/hmg/ddi467

23. Jann S, Bramerio MA, Beretta S, Koch S, Defanti CA, Toyka $\mathrm{KV}$, Sommer C (2003) Diagnostic value of sural nerve matrix metalloproteinase-9 in diabetic patients with CIDP. Neurology 61:1607-1610

24. Jones JI, Clemmons DR (1995) Insulin-like growth factors and their binding proteins: biological actions. Endocr Rev 16:3-34. doi:10.1210/edrv-16-1-3

25. Jones JI, Gockerman A, Busby WH Jr, Camacho-Hubner C, Clemmons DR (1993) Extracellular matrix contains insulin-like growth factor binding protein-5: potentiation of the effects of IGF-I. J Cell Biol 121:679-687

26. Kalus W, Zweckstetter M, Renner C, Sanchez Y, Georgescu J, Grol M, Demuth D, Schumacher R, Dony C, Lang K et al (1998) Structure of the IGF-binding domain of the insulin-like growth factor-binding protein-5 (IGFBP-5): implications for IGF and IGF-I receptor interactions. EMBO J 17:6558-6572. doi:10.1093/emboj/17.22.6558

27. Kelley KM, Oh Y, Gargosky SE, Gucev Z, Matsumoto T, Hwa V, Ng L, Simpson DM, Rosenfeld RG (1996) Insulin-like growth factor-binding proteins (IGFBPs) and their regulatory dynamics. Int J Biochem Cell Biol 28:619-637

28. Kimura J (2001) Techniques to assess muscle function. In: Electrodiagnosis in diseases of nerve and muscle: principles and practice. Oxford University Press, New York, pp 307-339

29. Krieger F, Elflein N, Saenger S, Wirthgen E, Rak K, Frantz S, Hoeflich A, Toyka KV, Metzger F, Jablonka S (2014) Polyethylene glycol-coupled IGF1 delays motor function defects in a mouse model of spinal muscular atrophy with respiratory distress type 1. Brain 137:1374-1393. doi:10.1093/brain/awu059

30. Liu JP, Baker J, Perkins AS, Robertson EJ, Efstratiadis A (1993) Mice carrying null mutations of the genes encoding insulin-like growth factor I (Igf-1) and type 1 IGF receptor (Igf1r). Cell 75:59-72

31. Lobsiger CS, Boillee S, McAlonis-Downes M, Khan AM, Feltri ML, Yamanaka K, Cleveland DW (2009) Schwann cells expressing dismutase active mutant SOD1 unexpectedly slow disease progression in ALS mice. Proc Natl Acad Sci 106:4465-4470. doi:10.1073/pnas.0813339106

32. Moyer-Mileur LJ, Slater H, Jordan KC, Murray MA (2008) IGF-1 and IGF-binding proteins and bone mass, geometry, and strength: relation to metabolic control in adolescent girls with type 1 diabetes. J Bone Miner Res 23:1884-1891. doi:10.1359/ jbmr.080713

33. Neff NT, Prevette D, Houenou LJ, Lewis ME, Glicksman MA, Yin QW, Oppenheim RW (1993) Insulin-like growth factors: putative muscle-derived trophic agents that promote motoneuron survival. J Neurobiol 24:1578-1588. doi:10.1002/ neu. 480241203

34. Nyenwe EA, Jerkins TW, Umpierrez GE, Kitabchi AE (2011) Management of type 2 diabetes: evolving strategies for the treatment of patients with type 2 diabetes. Metab Clin Exp 60:1-23. doi:10.1016/j.metabol.2010.09.010

35. Park IS, Kiyomoto H, Alvarez F, Xu YC, Abboud HE, Abboud SL (1998) Preferential expression of insulin-like growth factor binding proteins- $1,-3$, and -5 during early diabetic renal hypertrophy in rats. Am J Kidney Dis 32:1000-1010

36. Pastore C, Izura V, Geijo-Barrientos E, Dominguez JR (1999) A comparison of electrophysiological tests for the early diagnosis of diabetic neuropathy. Muscle Nerve 22:1667-1673 
37. Polydefkis M, Griffin JW, McArthur J (2003) New insights into diabetic polyneuropathy. JAMA 290:1371-1376. doi:10.1001/ jama.290.10.1371

38. Price GJ, Berka JL, Werther GA, Bach LA (1997) Cell-specific regulation of mRNAs for IGF-I and IGF-binding proteins-4 and -5 in streptozotocin-diabetic rat kidney. J Mol Endocrinol 18:5-14

39. Ramji N, Toth C, Kennedy J, Zochodne DW (2007) Does diabetes mellitus target motor neurons? Neurobiol Dis 26:301-311. doi:10.1016/j.nbd.2006.11.016

40. Said G (2007) Diabetic neuropathy-a review. Nat Clin Pract Neurol 3:331-340. doi:10.1038/ncpneuro0504

41. Schweizer U, Gunnersen J, Karch C, Wiese S, Holtmann B, Takeda K, Akira S, Sendtner M (2002) Conditional gene ablation of Stat3 reveals differential signaling requirements for survival of motoneurons during development and after nerve injury in the adult. J Cell Biol 156:287-297. doi:10.1083/jcb.200107009

42. Serbedzija P, Madl JE, Ishii DN (2009) Insulin and IGF-I prevent brain atrophy and DNA loss in diabetes. Brain Res 1303:179194. doi:10.1016/j.brainres.2009.09.063

43. Song SE, Kim YW, Kim JY, Lee DH, Kim JR, Park SY (2013) IGFBP5 mediates high glucose-induced cardiac fibroblast activation. J Mol Endocrinol 50:291-303. doi:10.1530/JME-12-0194

44. Stenvers KL, Zimmermann EM, Gallagher M, Lund PK (1994) Expression of insulin-like growth factor binding protein-4 and -5 mRNAs in adult rat forebrain. J Comp Neurol 339:91-105. doi:10.1002/cne. 903390109

45. Strotmeyer ES, de Rekeneire N, Schwartz AV, Faulkner KA, Resnick HE, Goodpaster BH, Shorr RI, Vinik AI, Harris TB, Newman AB (2008) The relationship of reduced peripheral nerve function and diabetes with physical performance in older white and black adults: the Health, Aging, and Body Composition (Health ABC) study. Diabetes Care 31:1767-1772. doi:10.2337/ dc08-0433

46. Syroid DE, Zorick TS, Arbet-Engels C, Kilpatrick TJ, Eckhart W, Lemke G (1999) A role for insulin-like growth factor-I in the regulation of Schwann cell survival. J Neurosci 19:2059-2068

47. Tan K, Baxter RC (1986) Serum insulin-like growth factor I levels in adult diabetic patients: the effect of age. J Clin Endocrinol Metab 63:651-655. doi:10.1210/jcem-63-3-651

48. Trujillo-Hernandez B, Huerta M, Trujillo X, Vasquez C, PerezVargas D, Millan-Guerrero RO (2005) F-wave and H-reflex alterations in recently diagnosed diabetic patients. J Clin Neurosci 12:763-766. doi:10.1016/j.jocn.2004.09.018

49. Uceyler N, Rogausch JP, Toyka KV, Sommer C (2007) Differential expression of cytokines in painful and painless neuropathies. Neurology 69:42-49. doi:10.1212/01.wnl.0000265062.92340.a5

50. Vincent AM, Russell JW, Low P, Feldman EL (2004) Oxidative stress in the pathogenesis of diabetic neuropathy. Endocr Rev 25:612-628. doi:10.1210/er.2003-0019

51. Wang H, Qin J, Gong S, Feng B, Zhang Y, Tao J (2014) Insulinlike growth factor-1 receptor-mediated inhibition of A-type $\mathrm{K}(+)$ current induces sensory neuronal hyperexcitability through the phosphatidylinositol 3-kinase and extracellular signal-regulated kinase 1/2 pathways, independently of Akt. Endocrinology 155:168-179. doi:10.1210/en.2013-1559

52. Wiese S, Herrmann T, Drepper C, Jablonka S, Funk N, Klausmeyer A, Rogers ML, Rush R, Sendtner M (2010) Isolation and enrichment of embryonic mouse motoneurons from the lumbar spinal cord of individual mouse embryos. Nat Protoc 5:31-38. doi:10.1038/nprot.2009.193

53. Wuarin L, Guertin DM, Ishii DN (1994) Early reduction in insulin-like growth factor gene expression in diabetic nerve. Exp Neurol 130:106-114. doi:10.1006/exnr.1994.1189

54. Yamanaka Y, Wilson EM, Rosenfeld RG, Oh Y (1997) Inhibition of insulin receptor activation by insulin-like growth factor binding proteins. J Biol Chem 272:30729-30734

55. Ye P, Carson J, D'Ercole AJ (1995) In vivo actions of insulinlike growth factor-I (IGF-I) on brain myelination: studies of IGF-I and IGF binding protein-1 (IGFBP-1) transgenic mice. J Neurosci 15:7344-7356

56. Zeslawski W, Beisel HG, Kamionka M, Kalus W, Engh RA, Huber R, Lang K, Holak TA (2001) The interaction of insulinlike growth factor-I with the N-terminal domain of IGFBP-5. EMBO J 20:3638-3644. doi:10.1093/emboj/20.14.3638

57. Zielasek J, Martini R, Toyka KV (1996) Functional abnormalities in $\mathrm{P} 0$-deficient mice resemble human hereditary neuropathies linked to P0 gene mutations. Muscle Nerve 19:946-952. doi:10.1002/ (SICI)1097-4598(199608)19:8<946:AID-MUS2>3.0.CO;2-8

58. Zylka MJ, Rice FL, Anderson DJ (2005) Topographically distinct epidermal nociceptive circuits revealed by axonal tracers targeted to Mrgprd. Neuron 45:17-25. doi:10.1016/j. neuron.2004.12.015 